\title{
Mesoporous Porphyrin-Silica Nanocomposite as Solid Acid Catalyst for High Yield Synthesis of HMF in Water
}

\author{
Arindam Modak ${ }^{1,+}+\mathbb{D}$, Akshay R. Mankar ${ }^{1,+}$, Kamal Kishore Pant ${ }^{1, *(D)}$ and Asim Bhaumik $2, *(\mathbb{D})$ \\ 1 Catalytic Reaction Engineering Lab, Department of Chemical Engineering, Indian Institute of Technology \\ Delhi, Delhi 110016, India; arindam_modak_2006@yahoo.co.in (A.M.); akshaymankar79@gmail.com (A.R.M.) \\ 2 School of Materials Sciences, Indian Association for the Cultivation of Science, 2A \& 2B Raja S. C. Mullick \\ Road, Jadavpur, Kolkata 700032, India \\ * Correspondence: kkpant@chemical.iitd.ac.in (K.K.P.); msab@iacs.res.in (A.B.) \\ + These authors contributed equally to this work.
}

Citation: Modak, A.; Mankar, A.R.; Pant, K.K.; Bhaumik, A. Mesoporous Porphyrin-Silica Nanocomposite as Solid Acid Catalyst for High Yield Synthesis of HMF in Water. Molecules 2021, 26, 2519. https://doi.org/ $10.3390 /$ molecules26092519

Academic Editor: Himanshu Sekhar Jena

Received: 29 March 2021 Accepted: 23 April 2021 Published: 26 April 2021

Publisher's Note: MDPI stays neutral with regard to jurisdictional claims in published maps and institutional affiliations.

Copyright: (c) 2021 by the authors. Licensee MDPI, Basel, Switzerland. This article is an open access article distributed under the terms and conditions of the Creative Commons Attribution (CC BY) license (https:// creativecommons.org/licenses/by/ $4.0 /)$.

\begin{abstract}
Solid acid catalysts occupy a special class in heterogeneous catalysis for their efficiency in eco-friendly conversion of biomass into demanding chemicals. We synthesized porphyrin containing porous organic polymers (PorPOPs) using colloidal silica as a support. Post-modification with chlorosulfonic acid enabled sulfonic acid functionalization, and the resulting material (PorPOPS) showed excellent activity and durability for the conversion of fructose to 5-hydroxymethyl furfural (HMF) in green solvent water. PorPOPS composite was characterized by $\mathrm{N}_{2}$ sorption, FTIR, TGA, CHNS, FESEM, TEM and XPS techniques, justifying the successful synthesis of organic networks and the grafting of sulfonic acid sites ( $5 \mathrm{wt} \%)$. Furthermore, a high surface area $\left(260 \mathrm{~m}^{2} / \mathrm{g}\right)$ and the presence of distinct mesopores of $\sim 15 \mathrm{~nm}$ were distinctly different from the porphyrin containing sulfonated porous organic polymer (FePOP-1S). Surprisingly the hybrid PorPOPS showed an excellent yield of HMF (85\%) and high selectivity ( $>90 \%)$ in water as compared to microporous pristine-FePOP-1S (yield of $\mathrm{HMF}=35 \%$ ). This research demonstrates the requirement of organic modification on silica surfaces to tailor the activity and selectivity of the catalysts. We foresee that this research may inspire further applications of biomass conversion in water in future environmental research.
\end{abstract}

Keywords: mesoporous porphyrin polymer; solid acid catalyst; fructose conversion; microwave synthesis in water; 5-hydroxymethyl furfural (HMF)

\section{Introduction}

The depletion of non-renewable fossil-derived resources is a prime concern for our society. It would be a major breakthrough if we could achieve considerable replacement of fossil fuels by renewable biomass-based feedstock as green fuel [1]. Among biomassderived platform chemicals, 5-hydroxymethyl furfural (HMF) is very demanding and versatile, since it can be transformed into numerous important chemicals, such as 2,5furandicarboxylic acid, 2,5-diformylfuran, levulinic acid and 2,5-dimethyl furan, which are precursors for polymers and fuels [2]. HMF was initially produced by dehydration of monosaccharides using homogeneous mineral acids like $\mathrm{HCl}, \mathrm{H}_{2} \mathrm{SO}_{4}$ and $\mathrm{HNO}_{3}$. However, their high corrosive properties as well as toxicity to the environment has motivated researchers to invent more user-friendly catalytic reactions. Moreover, soluble acids may create side reactions, decrease selectivity of the product, and be difficult to separate from the product mixtures. Commercial Amberlyst- 15 shows $80 \%$ HMF yield from fructose in DMSO and ionic liquid mixtures [3,4]. Though ionic liquids are explored in the synthesis of HMF from cellulose, their application using a biphasic solvent system, water-methyl isobutyl ketone, water-butanol, and water-THF is disadvantageous due to the issues of recyclability and the toxicity of applying organic solvents [5,6]. Thus, solid-supported catalysis for the synthesis of HMF is quite challenging under environmentally benign reaction conditions. High-density solid acids covalently embedded on a recyclable support [7] 
may catalyze this conversion processes very efficiently. HMF produced through solid acid catalysts, e.g., $\mathrm{AlCl}_{3}, \mathrm{SnCl}_{4}$, polyoxometalates, $\mathrm{WO}_{3} / \mathrm{SO}_{3} \mathrm{H}$-containing zirconia and cation exchange resins, show relatively lower product yield and poor selectivity in water [8-10]. Early research carried out with $\mathrm{FeCl}_{3}$, either in a batch reaction or using a continuous flow micro-reactor, shows promising advantages for fructose conversion to HMF in high yields [11]. Studies also report that sulfated $\mathrm{TiO}_{2}-\mathrm{ZrO}_{2}$ is an excellent dehydration catalyst that converts glucose or fructose to HMF [12]. Although solid acid catalysts are explored for the dehydration of biomass, high surface area, poor dispersibility and stability, and inadequate covalency between the active sites within the support may be problematic for consecutive recycling purposes. Although ordered mesoporous silica are well explored for one-pot conversion of biomass to HMF, post-functionalization of active sites on the silica support using organosilane are disadvantageous due to self-polymerization among silanes. Furthermore, accessible pores can also be blocked with this approach. In addition, reaction in neat water may be problematic due to poor solubility of HMF and low stability of hydrophilic silica. Under such circumstances, hydrophobic modification is required to tailor the activity and stability of silica supports [13].

Functional porous organic polymers (POPs) have a huge scope in solid catalysis because of their stability and scalability in synthesis as well as their tailorability in porous structures [14-16]. POPs possesses abundant surface-exposed aromatic sites for easy functionalization with surface bound Brønsted acids, which facilitates strong interaction with substrates [17]. However, controlling activity and selectivity with polymer-based catalysts remains a significant challenge due to microporosity and inadequate interaction with substrates. Hybrid catalysts are appealing, where inorganic components serve as support, and the organic modification may control diffusion and the product selectivity [18]. Rational design of hybrid catalysts thus remains challenging, particularly while accomplishing the reactions in water [19]. Herein, we report that POPs tethered on colloidal silica enriched with sulfonic acid facilitates fructose conversion in water, while the sulfonated porphyrin polymer marginally produces HMF in water under similar reaction conditions. Although related polymeric solid acids have been recently explored for one-pot conversion of fructose to HMF, poor yields were observed in water [20]. Thus, this research can offer significant opportunities for sustainable development of green catalysts for biomass conversion in water.

\section{Results}

\section{Synthesis and Characterization of PorPOPS}

Hybrid silica-porphyrin composite (PorPOPS) was prepared through a one-pot bottomup approach using solvothermal condensation polymerization of pyrrole and terephthalaldehyde [21,22]. To functionalize with sulfonic acids, post-functionalization was done with chlorosulfonic acid $\left(\mathrm{ClSO}_{3} \mathrm{H}\right)$, as shown in Scheme 1. Initial characterization by FESEM, TEM, $\mathrm{N}_{2}$ sorption, and XPS analysis confirms that porphyrin polymers are indeed functionalized by sulfonic acids and are coated with silica nanoparticles. Furthermore, we compared PorPOPS with un-functionalized PorPOP as well as FePOP-1. Porosity and pore size distribution was obtained from $\mathrm{N}_{2}$ sorption isotherms, as shown in Figure $1 \mathrm{a}-\mathrm{d}$. Both PorPOPS and PorPOP exhibited $\mathrm{N}_{2}$ uptake at low $\mathrm{P} / \mathrm{P}_{0}$, followed by flat interpolation within $(0.2-0.8) \mathrm{P} / \mathrm{P}_{0}$ and steep uptake beyond $0.8 \mathrm{P} / \mathrm{P}_{0}$, corresponding to the mesoporous materials [23]. In contrast, FePOP-1S showed microporosity, with steep uptake of $\mathrm{N}_{2}$ at low $\mathrm{P} / \mathrm{P}_{0}(<0.1)$ and almost linear extrapolation in the entire $\mathrm{P} / \mathrm{P}_{0}$ region $(0.1-0.99)$. These characteristics indicate that incorporation of silica during synthesis prevents the formation of microporous polymers and introduces extended inter-particle mesoporous materials. 

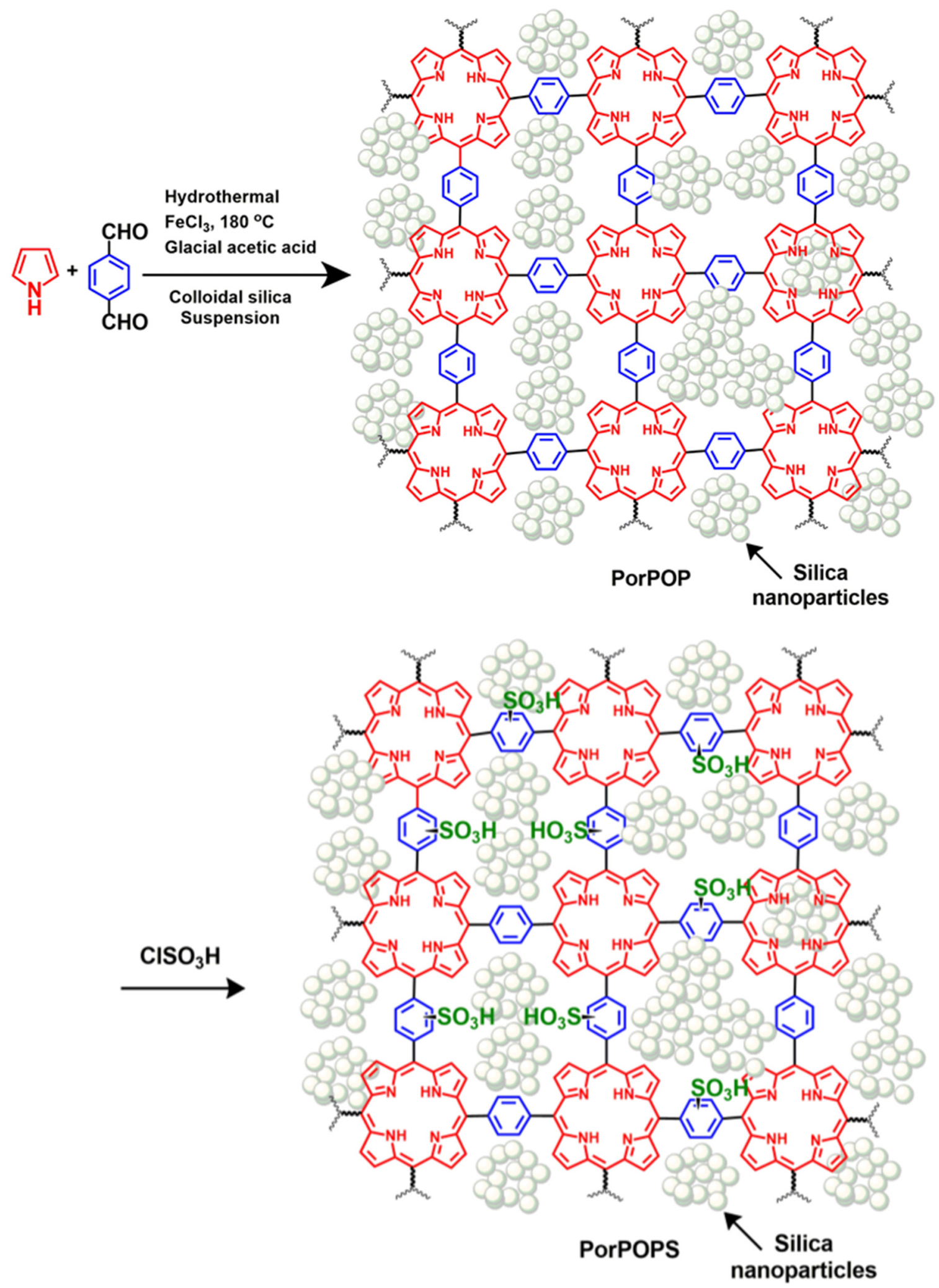

Scheme 1. Schematic representation for the synthesis of PorPOPS. 
(a)

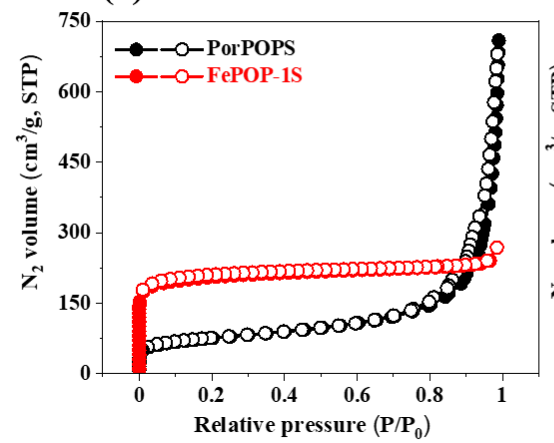

(d)

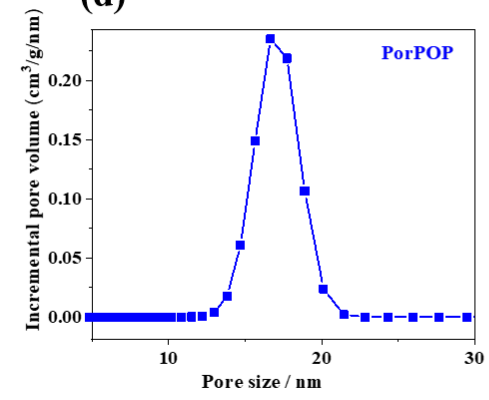

(b)

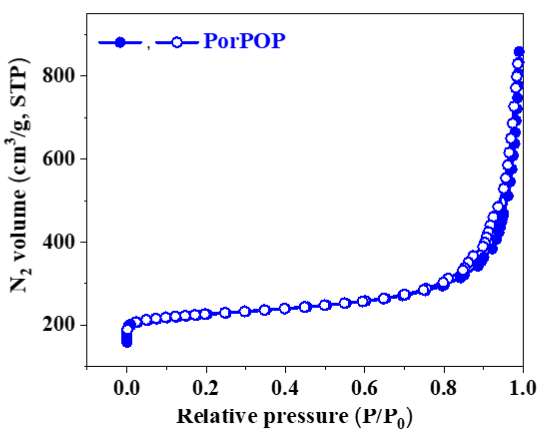

(e)

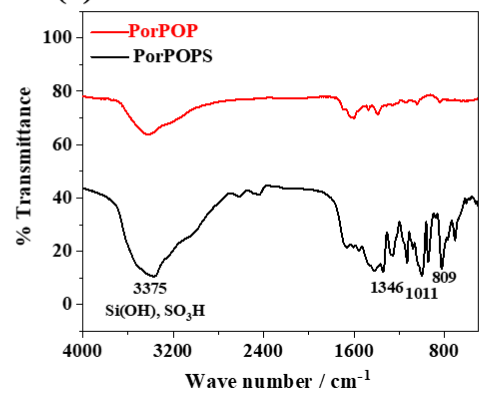

(c)

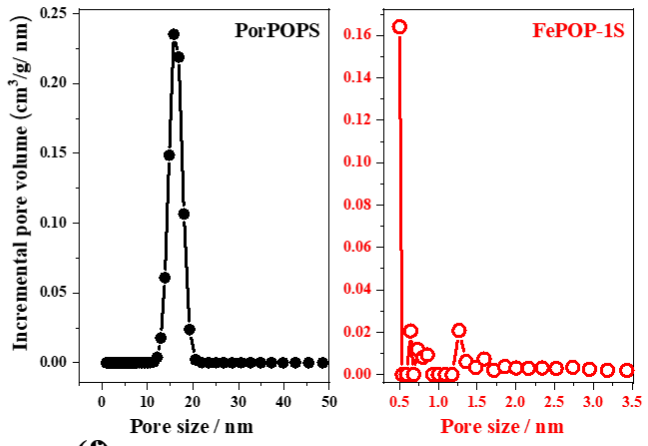

(f)

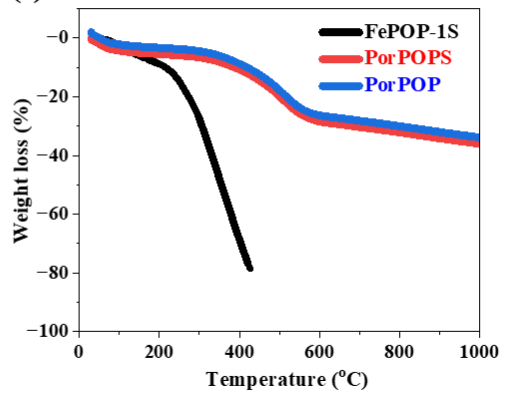

Figure 1. (a,b) $\mathrm{N}_{2}$-sorption isotherm; (c,d) pore size distribution; (e) FTIR-spectra; (f) TGA (air) analysis of Fe-POP-1S, PorPOP and PorPOPS.

The Brunauer-Emmett-Teller (BET) surface area was calculated to be 260 and $280 \mathrm{~m}^{2} / \mathrm{g}$ for PorPOPS and un-functionalized PorPOP, respectively, which is lower compared to the pristine porphyrin polymer (FePOP-1) $\left(860 \mathrm{~m}^{2} / \mathrm{g}\right)$ and even the sulfonated FePOP1S $\left(589 \mathrm{~m}^{2} / \mathrm{g}\right)$ because of the inclusion of silica nanoparticles that prevents accessible pores [22]. Pore size distribution of PorPOPS and PorPOP from Figure 1c, d clearly signify that the hybrid nanostructure contains distinct mesopores of $\sim 15 \mathrm{~nm}$, which is attributed primarily to the interparticle mesopores. In contrast, sulfonated FePOP-1S possesses small micropores $(0.5-1.5 \mathrm{~nm})$. It is noteworthy that, unlike microporous porphyrin, mesoporous hybrid PorPOPS could be advantageous as it obviates the diffusion limitation of substrates imposed by micropores [24]. Thus, with regard to the conversion of large biomass molecules like fructose, the developed organic-inorganic hybrid catalyst demands merit. Nevertheless, pore size has a profound influence on the yield as well as the selectivity of HMF, as shown by Du et al. [25]. Total pore volume was calculated from $\mathrm{N}_{2}$ sorption isotherm, and it was found to be $0.98 \mathrm{~cm}^{3} / \mathrm{g}$. This large pore volume is attributed to the presence of inter-particle mesopores. The FT-IR spectrum is shown in Figure 1e, where a sharp and high intense peak appears at $\sim 3374 \mathrm{~cm}^{-1}$, corresponding to the $-\mathrm{OH}$ of $-\mathrm{SO}_{3} \mathrm{H}$ and silica particles in PorPOPS.

The existence of a porphyrin ring in PorPOPS is attributed to the presence of bands at 1267 and $1137 \mathrm{~cm}^{-1}$, corresponding to the $\mathrm{C}-\mathrm{N}$ stretching of pyrrole. Subsequently, other bands at 1668 and $1430 \mathrm{~cm}^{-1}$ are due to phenyl $\mathrm{C}=\mathrm{C}$ stretching in the porphyrin ring [26]. Symmetric and asymmetric stretching of $\mathrm{C}-\mathrm{S}$ and $\mathrm{C}-\mathrm{SO}_{3} \mathrm{H}$ were observed at 471 , 1075 and $1350 \mathrm{~cm}^{-1}$ [27]. Such characteristics are assigned the confirmation of sulfonic acid in PorPOPS, whereas these bands are absent in un-functionalized PorPOP. A TGA plot is shown in Figure 1f; it suggests a stable framework up to $400{ }^{\circ} \mathrm{C}$ (weight loss ca. $~ 10 \%$ ). Total weight loss of $\sim 37 \%$ up to $1000{ }^{\circ} \mathrm{C}$ suggests that PorPOPS and PorPOP consists of $\sim 27 \%$ organic groups (porphyrin functionality). The sulfonated organic polymer, FePOP-1S, is stable up to $280^{\circ} \mathrm{C}$ (weight loss ca. $10 \%$ ) and completely collapses above $400{ }^{\circ} \mathrm{C}$. This result suggests that PorPOPS and PorPOP, composed of a hybrid composite containing both porphyrin and silica functionality, have considerably high thermal stability over the porphyrin polymer alone. 
Morphology was confirmed from TEM and FESEM image analyses; it suggests an agglomerated nanostructure of PorPOPS and PorPOP, containing silica nanoparticles. It shows that 150-250 nm porphyrin polymers are surrounded by smaller silica spheres of about $30 \mathrm{~nm}$ (Figures 2 and 3). The spherical shape of pristine (FePOP-1) and the sulfonated porphyrin nanoparticles (FePOP-1S) are evidenced from both TEM and SEM images, with a wider distribution of particles (150-300 $\mathrm{nm}$ ).

Chemical composition of the surface was assigned through X-ray photoelectron spectroscopic (XPS) analysis (Figure 4). Deconvoluted N1s spectrum in PorPOPS confirms the existence of pyrrolic and pyridinic moieties, centered at 399.8 and $398.9 \mathrm{eV}$, respectively [28]. However, XPS shows no existence of either oxidized nitrogen or graphitic nitrogen beyond $400 \mathrm{eV}$ [29]. Thus, XPS infers the appearance of a large pyrrolic band corresponding to the porphyrin moiety of PorPOPS. Hence, this suggests that PorPOPS is stable under strong acid treatment. Interestingly, intensity of the pyridinic band is suppressed in PorPOPS in contrast to un-functionalized PorPOP, which might be because of the protonated porphyrin in PorPOPS. Successful grafting of sulfonic acid is further confirmed from the deconvoluted S2p spectrum. A fitted doublet appears at 167 and $168.5 \mathrm{eV}$ and accompanies a broad shoulder at $162.2 \mathrm{eV}$. The strong band at $168.5 \mathrm{eV}$ resembles a sulfonate band, while another band appearing at $167 \mathrm{eV}$ could be attributed to oxidized sulfone $\left(-\mathrm{SO}_{2}-\right)$. On the other hand, the broad shoulder may originate from organic disulfide-type residues [30]. Considering elemental analysis from XPS, higher pyrrolic $(70 \%)$ to pyridinic $(30 \%)$ ratio and a better sulfone (58\%) to sulfonate $(52 \%)$ ratio can be predicted. Furthermore, CHNS analysis reveals the possibility of $\sim 5.0 \mathrm{wt} \%$ sulfonic acid sites in PorPOPS. Thus, the above results clearly demonstrate that a sulfonic-acid-rich porphyrin network is successfully formed in PorPOPS.
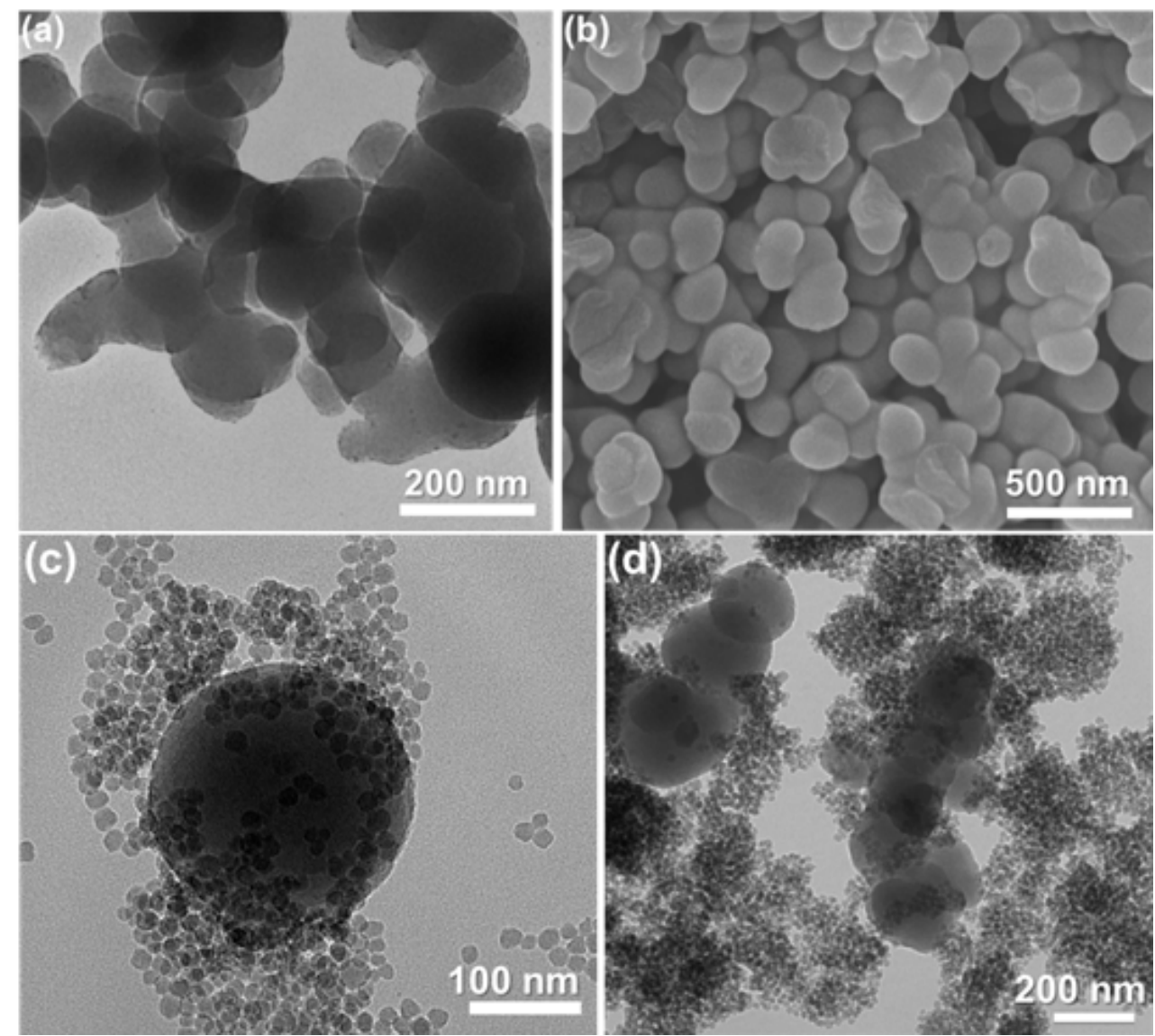

Figure 2. TEM (a) and FESEM (b) image of pristine porphyrin polymer (FePOP-1); (c,d) TEM image of PorPOPS. 

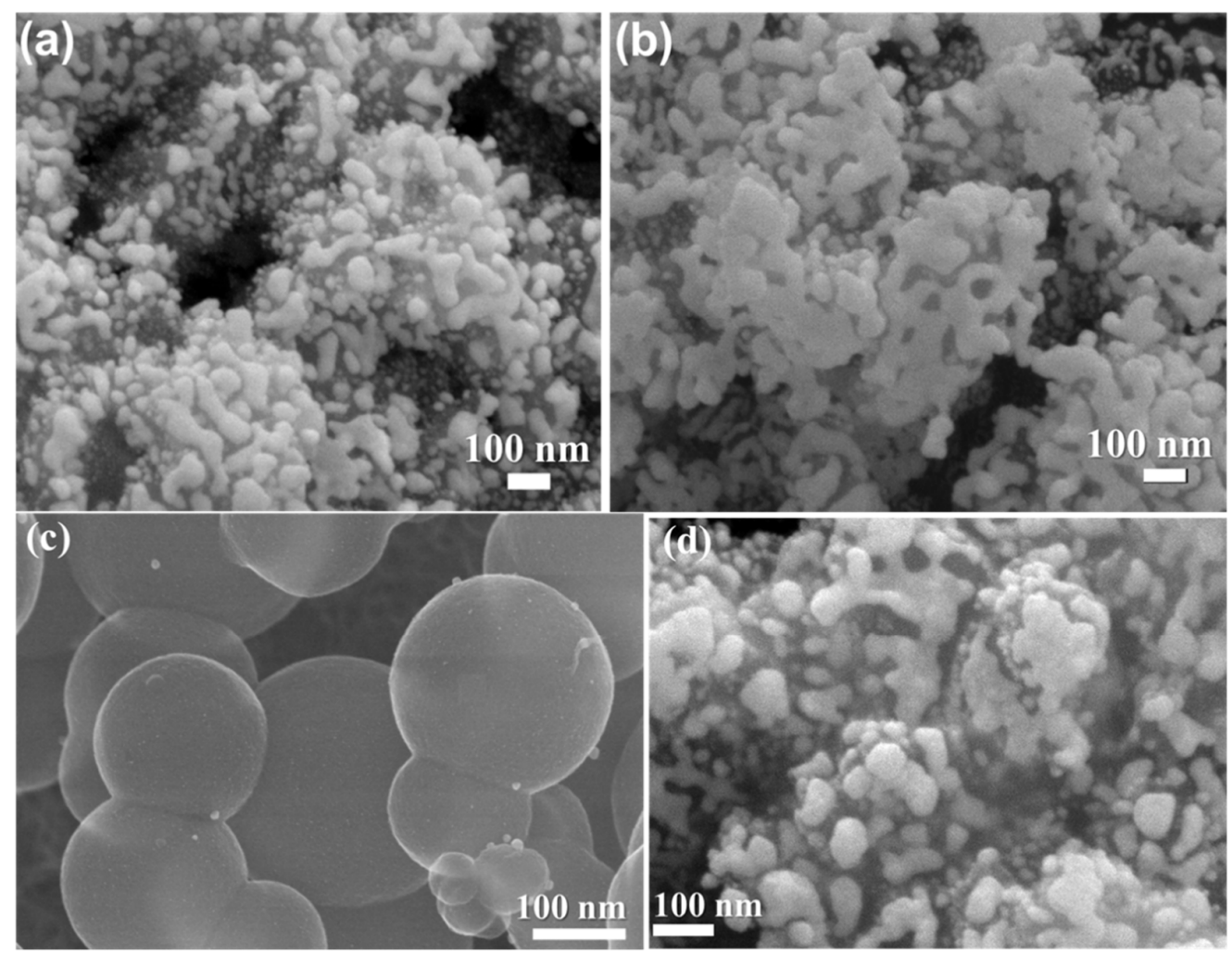

Figure 3. FESEM images of (a,b) sulfonated porphyrin silica composite, PorPOPS, (c) FePOP-1S, (d) un-functionalized PorPOP.

(a)

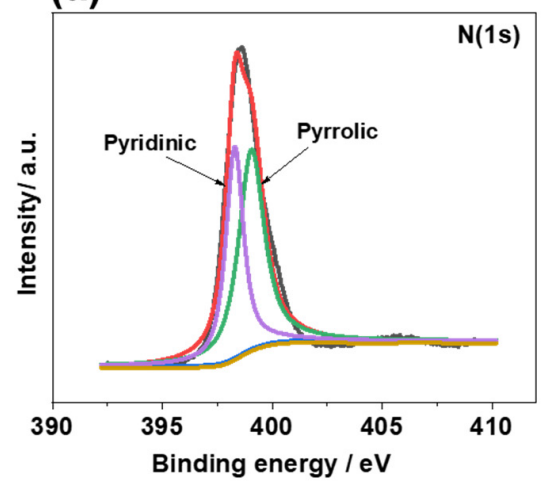

(c)

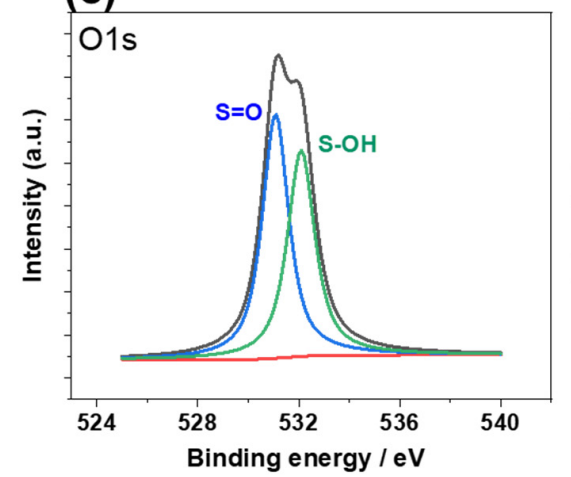

(b)

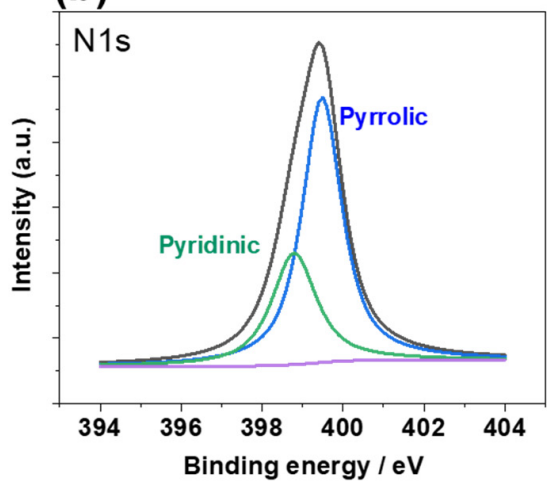

(d)

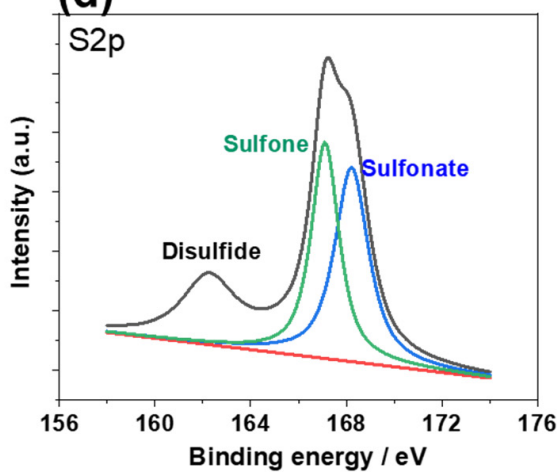

Figure 4. XPS spectra of (a) N1s of PorPOP and (b-d) PorPOPS containing N1s, O1s and S2p, respectively. 


\section{Discussion}

A high surface area and the presence of accessible sulfonic acids in PorPOPS motivated us to explore its catalytic activity towards fructose dehydration reactions (Scheme 2).

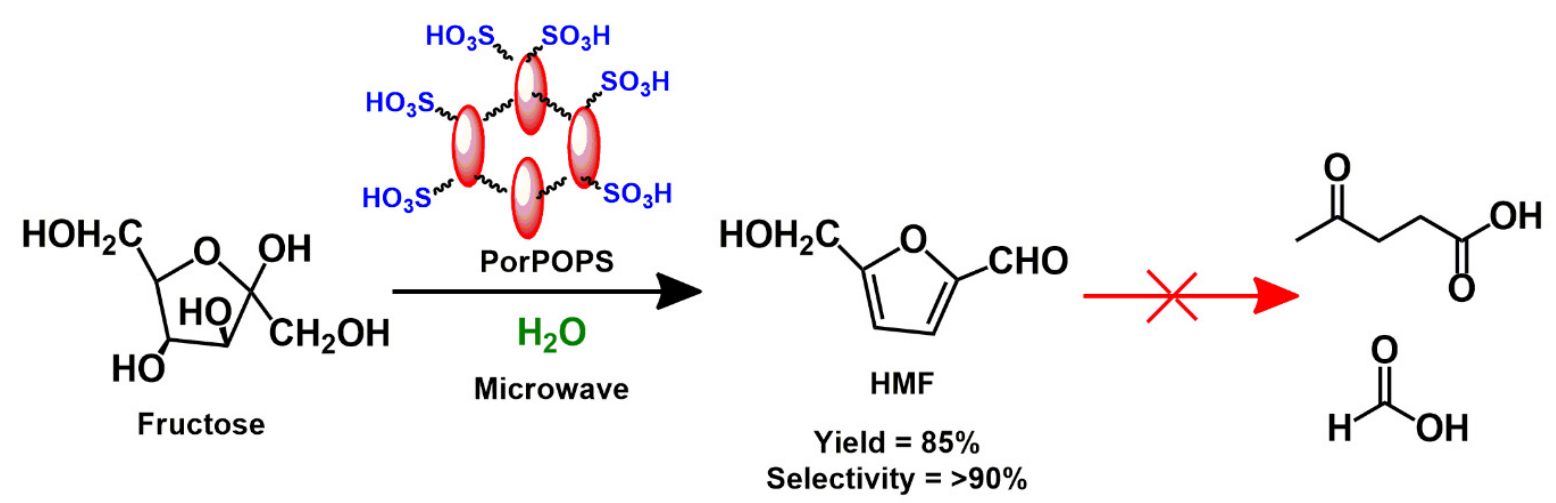

Scheme 2. One-pot green conversion of fructose to HMF using PorPOPS.

Initial screening of the reaction in a microwave reactor was done at different temperatures and times using various amounts of catalyst to optimize the reaction conditions. Contrary to the literature, we obtained the highest HMF yield in water; thus, all the reactions were carried out using water only as a solvent. The effect of temperature on the fructose conversion and the yield of HMF was thoroughly studied within 130 to $180{ }^{\circ} \mathrm{C}$ (Figure 5a). Initially, at $130{ }^{\circ} \mathrm{C}$, only $15 \%$ fructose was converted to $13 \% \mathrm{HMF}$ (yield). Further increases in temperature (from 130 to $160{ }^{\circ} \mathrm{C}$ ) led to a significant improvement in both the conversion and yield, where highest $\mathrm{HMF}$ yield $(85 \%)$ was observed at $160^{\circ} \mathrm{C}$. Although fructose conversion $(>95 \%)$ progressively increased at higher temperatures $\left(>160^{\circ} \mathrm{C}\right)$, HMF yield was reduced from $85 \%\left(160{ }^{\circ} \mathrm{C}\right)$ to $39 \%\left(170{ }^{\circ} \mathrm{C}\right)$ and $13 \%\left(180{ }^{\circ} \mathrm{C}\right)$, which indicates fructose dehydration is highly sensitive to temperature, and an optimum temperature is necessary to maintain high HMF selectivity, as other side products (levulinic acid, formic acid) are commonly observed beyond $170^{\circ} \mathrm{C}$ [31]. Again, polycondensation of fructose may also reduce $\mathrm{HMF}$ selectivity at $170{ }^{\circ} \mathrm{C}$ [32]. Thus, kinetic study was done at $160^{\circ} \mathrm{C}$, as shown in Figure $5 b$.

At $0.5 \mathrm{~h}$, lower conversion $(46 \%)$ and yield $(47 \%)$ were observed. Further prolonging the reaction to $2 \mathrm{~h}, \mathrm{HMF}$ yield was improved to $85 \%$, but decreased to $63 \%$ at $2.5 \mathrm{~h}$ (Figure $5 b$ ), possibly because of humin formation from fructose decomposition $[33,34]$. Thus, the controlled experiments suggest that $160^{\circ} \mathrm{C} / 2 \mathrm{~h}$ is the most suitable condition to achieve the highest HMF yield over PorPOPS. Since fructose dehydration is dependent on the total Brønsted acidity, variation of the catalyst dosage may change the reaction rate. For this, catalyst dosage was varied from $0.005 \mathrm{~g}(0.1 \mathrm{mmol} / \mathrm{g}$ sulfonic acid) to $0.02 \mathrm{~g}$ ( $0.4 \mathrm{mmol} / \mathrm{g}$ sulfonic acid); the highest yield of HMF occurred when $10 \mathrm{mg}$ catalyst was used, which was subsequently reduced at higher loading, as shown in Figure 5c. Thus, a higher catalyst amount results in decomposition or degradation of fructose to other byproducts. Recyclability of PorPOPS was tested up to five cycles; HMF yield was reduced to $\sim 70 \%$ after the 5th cycle, in contrast to the fresh catalyst (85\%) (Figure 6a). Additionally, the sulfonated porphyrin FePOP- $1 \mathrm{~S}$ was sustained up to five recycle runs, and $\sim 14 \%$ loss of HMF yield was observed at the end of the 5th cycle. This result shows that sulfonated porphyrin with/without functionalization by silica nanoparticles is advantageous as a solid catalyst in water. Nevertheless, the un-functionalized PorPOP and FePOP-1 which do not have any sulfonic acid sites, cannot exhibit HMF yield (Table 1, Rows 13-14). However, due to feeble acidity of silica hydroxyl sites, only $5 \%$ fructose is converted with PorPOP. This result suggests that a cooperative interaction between porphyrin, silica and sulfonic acids in PorPOPS is essential for maximum conversion of fructose to HMF. A comparative study with other contemporary catalysts, e.g., porous carbon, zeolite, metal-organic frameworks (MOF) and metal oxides, is shown in Table 1. 

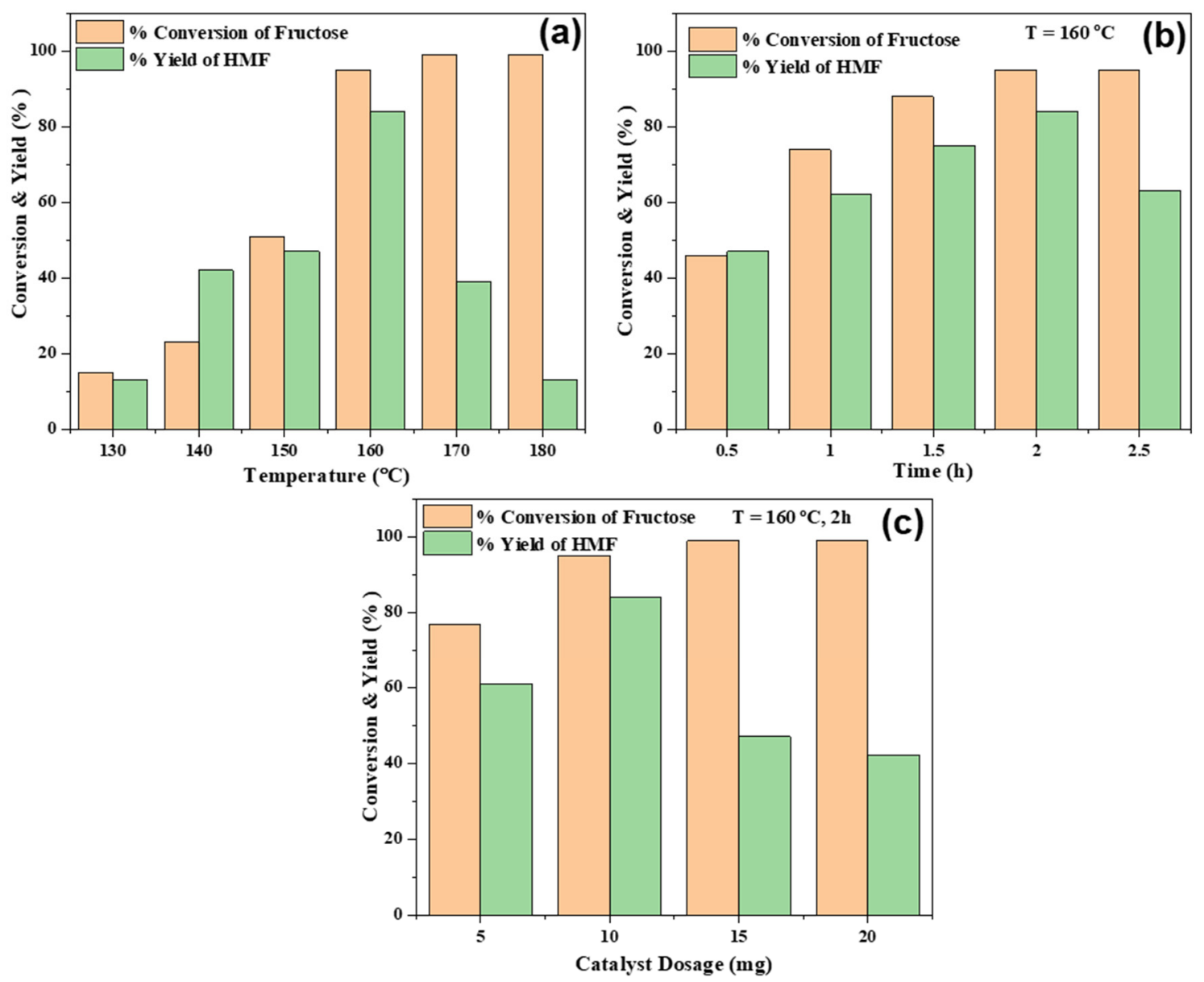

Figure 5. Effect of temperature (a), time (b) and catalyst dosage (c) for PorPOPS catalysed conversion of fructose to HMF in $2 \mathrm{~mL}$ water.
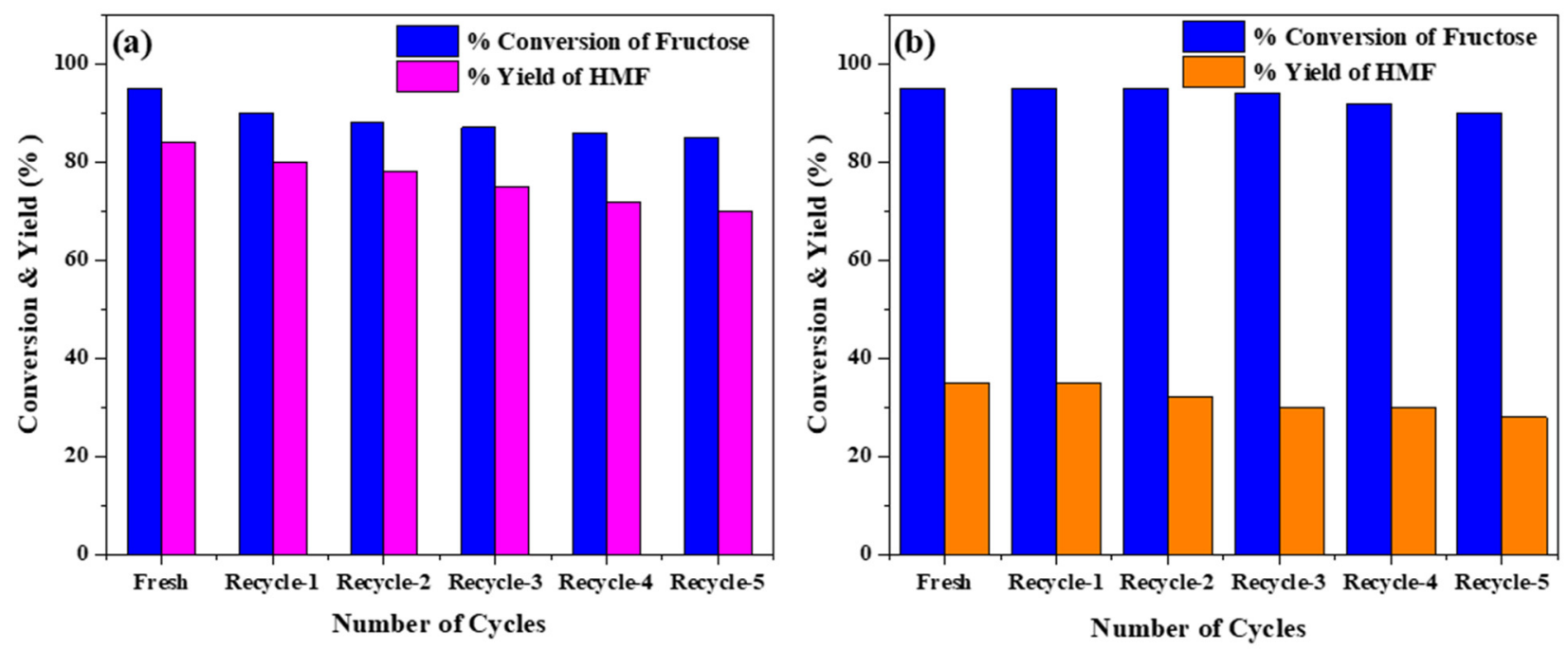

Figure 6. Recyclability study of (a) PorPOPS and (b) sulfonated porphyrin polymers (FePOP-1S) for fructose dehydration reaction to HMF (reaction conditions: $0.01 \mathrm{~g}$ fructose $\left(0.04 \mathrm{mmol} / \mathrm{g}\right.$ sulfonic acid), $2 \mathrm{~mL}$ water, $\left.160{ }^{\circ} \mathrm{C}, 2 \mathrm{~h}\right)$. 
Table 1. Comparative study of PorPOPS in fructose conversion to HMF in water.

\begin{tabular}{|c|c|c|c|c|c|}
\hline Entry & $\begin{array}{l}\text { Reaction } \\
\text { Conditions }\end{array}$ & Catalyst & $\begin{array}{l}\text { Conversion of } \\
\text { Fructose }(\%)\end{array}$ & Yield of HMF (\%) & Reference \\
\hline 1 & $120^{\circ} \mathrm{C}, 16 \mathrm{~h}$ & $\begin{array}{c}\text { Phosphorylated mesoporous } \\
\text { carbon }\end{array}$ & 78 & 41.3 & {$[35]$} \\
\hline 2 & $100^{\circ} \mathrm{C}, 3 \mathrm{~h}$ & Niobium phosphate & 51.2 & 30.4 & [36] \\
\hline 3 & $180^{\circ} \mathrm{C}, 10 \mathrm{~min}$ & Niobium phosphate & 86.5 & 33.9 & \multirow{2}{*}[37]{} \\
\hline 4 & $190^{\circ} \mathrm{C}, 8 \mathrm{~min}$ & Zirconium phosphate & 96.3 & 39.4 & \\
\hline 5 & $170^{\circ} \mathrm{C}, 4.5 \mathrm{~h}$ & $\begin{array}{l}\text { Phosphoric acid } \\
\text { functionalized carbon catalyst }\end{array}$ & 100 & 59.9 & {$[38]$} \\
\hline 6 & $120^{\circ} \mathrm{C}, 24 \mathrm{~h}$ & Amberlyst-15 & 57 & 15 & [39] \\
\hline 7 & $165^{\circ} \mathrm{C}, 3 \mathrm{~h}$ & $\mathrm{TiO}_{2}-\mathrm{SO}_{3} \mathrm{H}$ & 99 & 50 & [40] \\
\hline 8 & $140^{\circ} \mathrm{C}, 5 \mathrm{~h}$ & NU-1000 & 60 & 2.3 & \multirow{2}{*}[41]{} \\
\hline 9 & $140^{\circ} \mathrm{C}, 5 \mathrm{~h}$ & $\mathrm{PO}_{4} / \mathrm{NU}($ half) & 50 & 15 & \\
\hline 10 & $120^{\circ} \mathrm{C}, 1 \mathrm{~h}$ & SBA-15- $\mathrm{SO}_{3} \mathrm{H}$ & 100 & 30 & [42] \\
\hline 11 & $160^{\circ} \mathrm{C}, 2 \mathrm{~h}$ & $\begin{array}{l}\text { Sulfonated porphyrin } \\
\text { polymer (FePOP-1S) }\end{array}$ & 95 & 35 & This study \\
\hline 12 & $160^{\circ} \mathrm{C}, 2 \mathrm{~h}$ & PorPOPS & 95 & 85 & This study \\
\hline 13 & $160^{\circ} \mathrm{C}, 2 \mathrm{~h}$ & Un-functionalized PorPOP & $<5$ & traces $(<1)$ & This study \\
\hline 14 & $160^{\circ} \mathrm{C}, 2 \mathrm{~h}$ & Un-functionalized FePOP-1 & No & No & This study \\
\hline
\end{tabular}

Interestingly, PorPOPS shows highest HMF yield among the contemporary solid acid catalysts. It is noteworthy that stability could be an issue for MOFs in water, as shown by Corma and Boronat. Importantly, it was shown that high HMF yield in water can be achieved under anaerobic conditions in nitrogen (1 bar) atmosphere [43]. Interestingly, the effect of silica on PorPOPS is significant, where microporous sulfonated porphyrin polymer synthesized in the absence of colloidal silica showed lower HMF yield (35\%) under similar conditions. Unlike sulfonated porphyrin POP, unique mesoporosity, together with hydrophilic coating of silica on the hydrophobic surface, may be advantageous for the activation and dehydration of fructose to HMF. Thus, for fructose conversion, PorPOPS is advantageous in water, possibly due to its high surface area and good accessibility of aromatic sulfonic acids towards substrates, as previously observed by Schüth et al. [44].

\section{Materials and Methods}

\subsection{Chemicals}

Pyrrole ( $\geq 98 \%)$, anhydrous $\mathrm{FeCl}_{3}(99 \%)$, glacial acetic acid ( $\left.\geq 99 \%\right)$, chlorosulfonic acid $(99 \%)$, terephthalaldehyde (99\%), anhydrous 1,2-dichloroethane $(99.8 \%)$, fructose ( $\geq 99 \%)$, 5-hydroxymethylfurfural ( $\geq 99 \%)$, sulfuric acid (99\%), colloidal silica (Ludox, AS-40) and HPLC-grade water were purchased from Sigma Aldrich, St. Louis, MO, USA. All chemicals were used as received, without any further purification.

\subsection{Instrumentation}

$\mathrm{N}_{2}$ adsorption-desorption isotherms were measured at $-196^{\circ} \mathrm{C}$ using a Quantachrome Instruments (A brand of Anton Paar, Boynton Beach, Florida, USA) Autosorb 1C surface area analyzer. Prior to the analysis, samples were degassed at $150{ }^{\circ} \mathrm{C}$ for $5 \mathrm{~h}$ under high vacuum. Pore size was analyzed with a density functional theory (DFT) model using $\mathrm{N}_{2}$ at $77 \mathrm{~K}$ on carbon cylindrical pores. The thermal stability of the samples was measured by thermogravimetry analysis (TGA) using a NETZSCH STA 449F3 analyser (NETZSCH, Selb, Germany) within the temperature range $25-1000{ }^{\circ} \mathrm{C}$ at a heating rate of $10^{\circ} \mathrm{C} / \mathrm{min}$ in air. Xray photoelectron spectroscopy (XPS) was recorded by VG ESCALAB MK2 (ThermoFisher 
Scientific, Waltham, MA, USA) using AlK $\alpha(\mathrm{h} \lambda=1486.6 \mathrm{eV})$ as the excitation source. Fourier transform infrared spectra (FT-IR) were documented on a Nicolet Nexus 470 IR spectrometer (ThermoFisher Scientific, Waltham, MA, USA). Field-emission scanning electron microscopy (JEOL JEM 6700F FE SEM, JEOL, Tokyo, Japan) was used to examine the morphology of powder samples. Transmission electron microscopy (TEM) experiments were executed using HITACHI HT7700 (HITACHI, Tokyo, Japan) at an acceleration voltage of $100 \mathrm{kV}$. Carbon, hydrogen and nitrogen contents were determined using a Perkin Elmer 2400 Series II CHN analyzer (Perkin Elmer, Waltham, MA, USA).

\subsection{Synthesis of Organic-Inorganic Hybrid Silica-Porphyrin Conjugated Polymers (PorPOPs)}

A porphyrin polymer (FePOP-1) was reproduced from our previous report after slight modification of the procedure [22]. Initially, terephthalaldehyde $(0.2 \mathrm{~g}, 1.5 \mathrm{mmol})$ was taken in a $100 \mathrm{~mL}$ well dried beaker and was dissolved in $15 \mathrm{~mL}$ of glacial acetic acid under constant stirring for $10 \mathrm{~min}$. Next, freshly distilled pyrrole $(0.1 \mathrm{~g}$; $1.5 \mathrm{mmol})$ was added to the solution and stirred for $20 \mathrm{~min}$ with the addition of $5 \mathrm{~mL}$ colloidal silica. Anhydrous $\mathrm{FeCl}_{3}(0.32 \mathrm{~g} ; 2 \mathrm{mmol})$ was added to the solution, and stirring was continued to $12 \mathrm{~h}$ under $\mathrm{N}_{2}$ atmosphere. The brownish mixture was transferred to a Teflon-lined autoclave and was subjected to hydrothermal treatment at $180^{\circ} \mathrm{C}$ for $48 \mathrm{~h}$ under a static condition. The dark brownish precipitate was then filtered and washed thoroughly with distilled water, methanol and THF to remove all iron-based impurities and then dried in an oven at $80{ }^{\circ} \mathrm{C}$ for $24 \mathrm{~h}$ (named as PorPOP). The yield of polymer was $25 \%$ based on terephthalaldehyde, and the elemental analysis (wt\%) was $\mathrm{C}, 80.0 ; \mathrm{H}, 4.1 ; \mathrm{N}, 8.5$.

\subsection{Synthesis of PorPOPS Through Post-Functionalization with Chlorosulfonic Acid}

A total of $0.3 \mathrm{~g}$ PorPOP was dispersed in $10 \mathrm{~mL}$ anhydrous 1,2-dichloromethane through sonication for $5 \mathrm{~min}$. The slurry mixture was cooled in an ice bath, and chlorosulfonic acid $(2 \mathrm{~mL})$ was then added slowly to the solution and stirred for three days at $25{ }^{\circ} \mathrm{C}$. After completion, the dark brownish solution was poured on ice, centrifuged, and washed thoroughly with water until $\mathrm{pH}$ was neutral. Then, the catalyst was dried in an oven overnight and named PorPOPS. Elemental analysis (wt\%) was as follows: C, 30; H, 3.1; N, 5.2; $\mathrm{S}, 5$. The total acid strength of PorPOPS was measured through acid-base titration and was $1.96 \mathrm{mmol} / \mathrm{g}$.

Un-functionalized porphyrin polymer (FePOP-1) in absence of silica was reproduced from a previous report [22] and was post-functionalized with sulfonic acid following the procedure mentioned above. The sulfonic acid functionalized organic polymer was named Fe-POP-1S.

\subsection{One-Pot Conversion of Fructose to HMF}

All fructose dehydration reactions were performed using a microwave reactor (Anton Paar: Monowave 300, Anton Paar, Graz, Austria) with operation limits of $300{ }^{\circ} \mathrm{C}$ and 30 bar. In a typical reaction, $0.02 \mathrm{~g}$ fructose, PorPOPS (0.005 to $0.02 \mathrm{~g})$ and $2 \mathrm{~mL}$ water was fed in the borosilicate glass vial. A magnetic bead was placed in the vial for stirring and the sealed vial was placed in the reactor cavity. Then, a series of reactions were performed under different temperatures $\left(130\right.$ to $\left.180^{\circ} \mathrm{C}\right)$ for varying reaction times $(0.5 \mathrm{~h}$ to $2.5 \mathrm{~h})$ using the as-fast-as-possible heating mode of the microwave reactor [45]. After the completion of the reaction, the reactor was cooled down to room temperature using the cooling system provided with the reactor. All the reactions were performed at least twice, and the average of the results were reported.

\subsection{Product Analysis}

After the reaction, the catalyst was separated from the liquid product mixture using filtration. Then, the liquid samples were passed through a micro-syringe filter before analysing the samples using high-performance liquid chromatography (HPLC). HPLC (Agilent 1200 infinity series (Agilent Technologies, Santa Clara, CA, USA) equipped with 
an autosampler, refractive index (RI) detector, ultraviolet (UV) detector, and Aminex HPX-87H column (Bio-Rad Laboratories, Irvine, CA, USA) $(300 \times 7.8 \mathrm{~mm})$ was used for the quantification of fructose and HMF. An injection volume of $2 \mu \mathrm{L}$ and flow rate of $0.6 \mathrm{~mL} / \mathrm{min}$ were fixed, and sulphuric acid $(5 \mathrm{mM})$ was used as the mobile phase. The column temperature was maintained at $50{ }^{\circ} \mathrm{C}$, and the $\mathrm{UV}$ detector was set at a wavelength of $284 \mathrm{~nm}$ for the detection of HMF. All the samples were injected twice, and the average readings were used for the calculation of the fructose conversion and the calculation of HMF yield, using the following equations (Equations (1) and (2)), based on their mass in the feed:

$\%$ Conversion of fructose $=\frac{\text { initial amount of fructose fed }- \text { amount of unreacted fructose }}{\text { initial amount of fructose fed }} \times 100$

$$
\% \text { Yield of HMF }=\frac{\text { amount of HMF produced }}{\text { initial amount of fructose fed }} \times 100
$$

\section{Conclusions}

Experimental results shown herein suggest that sulfonated porous porphyrin polymer impregnated with silica nanoparticles is an efficient solid acid catalyst for one-pot conversion of biomass-derived fructose to HMF. Remarkably, HMF yield (85\%) in water is higher than that reported over related solid acid catalysts. This could be due to its high porosity accompanied by high loading of accessible surface sulfonic acid groups at the catalyst surface. Although aromatic sulfonates are demanding in acid catalysis, desulfonation and humin formation is a problematic issue for biomass conversion at high temperature reactions. Sulfonic acid functionalized POPs with silica support can afford excellent yield of HMF from biomass-derived carbohydrates, and there is a huge opportunity to scale up this conversion beyond the laboratory.

\section{Patents}

An Indian Patent for the work reported in this manuscript has been filed (Application No.: 202111012815).

Author Contributions: A.M. and A.R.M. designed the experiments, synthesized the catalysts and performed the chemical reactions. A.M. wrote the manuscript with the help of A.R.M., K.K.P. and A.B. K.K.P. and A.B. revised the manuscript and supervised the project. All authors have read and agreed to the published version of the manuscript.

Funding: A.M., A.R.M. and K.K.P. gratefully acknowledge DST/SERB (CRG/2019/005613) for providing the funding. K.K.P. would like to thank the Petrotech Society of India for the Petrotech Chair Professorship grant.

Data Availability Statement: Data are available from the authors on request.

Acknowledgments: The authors kindly acknowledge IIT-Delhi for providing support and infrastructure.

Conflicts of Interest: The authors declare no conflict of interest.

Sample Availability: Samples of the compounds are available from the authors.

\section{References}

1. Alonso, D.M.; Wettstein, S.G.; Dumesic, J.A. Gamma-valerolactone, a sustainable platform molecule derived from lignocellulosic biomass. Green Chem. 2013, 15, 584-595. [CrossRef]

2. Serrano-Ruiz, J.C.; Luque, R.; Sepúlveda-Escribano, A. Transformations of biomass-derived platform molecules: From high added-value chemicals to fuelsvia aqueous-phase processing. Chem. Soc. Rev. 2011, 40, 5266-5281. [CrossRef]

3. Sampath, G.; Kannan, S. Fructose dehydration to 5-hydroxymethylfurfural: Remarkable solvent influence on recyclability of Amberlyst-15 catalyst and regeneration studies. Catal. Commun. 2013, 37, 41-44. [CrossRef]

4. Qi, X.; Watanabe, M.; Aidaa, T.M.; Smith, R.L., Jr. Efficient process for conversion of fructose to 5-hydroxymethylfurfural with ionic liquids. Green Chem. 2009, 11, 1327-1331. [CrossRef]

5. Rosatella, A.A.; Simeonov, S.P.; Fradea, R.F.M.; Afonso, C.A.M. 5-Hydroxymethylfurfural (HMF) as a building block platform: Biological properties, synthesis and synthetic applications. Green Chem. 2011, 13, 754-793. [CrossRef] 
6. Huynh, N.T.T.; Lee, K.W.; Cho, J.K.; Kim, Y.J.; Bae, S.W.; Shin, J.S.; Shin, S. Conversion of D-fructose to 5-acetoxymethyl-2-furfural using immobilized lipase and cation exchange resin. Molecules 2019, 24, 4623. [CrossRef] [PubMed]

7. Shimizu, K.; Uozumi, R.; Satsuma, A. Enhanced production of hydroxymethylfurfural from fructose with solid acidcatalysts by simple water removal methods. Catal. Commun. 2009, 10, 1849-1853. [CrossRef]

8. Wang, Z.; Chen, Q. Conversion of 5-hydroxymethylfurfural into 5-ethoxymethylfurfural and ethyl levulinate catalyzed by MOF-based heteropolyacid materials. Green Chem. 2016, 18, 5884-5889. [CrossRef]

9. Gupta, D.; Ahmad, E.; Pant, K.K.; Saha, S. Efficient utilization of potash alum as a green catalyst for production of furfural, 5-hydroxymethylfurfural and levulinic acid from mono-sugars. RSC Adv. 2017, 7, 41973-41979. [CrossRef]

10. Zhou, D.; Shen, D.S.; Lu, W.J.; Song, T.; Wang, M.Z.; Feng, H.J.; Shentu, J.L.; Long, Y.Y. Production of 5-hydroxymethylfurfural from chitin biomass: A review. Molecules 2020, 25, 541. [CrossRef] [PubMed]

11. Tuercke, T.; Panic, S.; Loebbecke, S. Microreactor process for the optimized synthesis of 5-hydroxymethylfurfural: A promising building block obtained by catalytic dehydration of fructose. Chem. Eng. Technol. 2009, 32, 1815-1822. [CrossRef]

12. Zhang, J.; Wu, S.B.; Zhang, H.D.; Li, B. Conversion of glucose over $\mathrm{SO}_{4}{ }^{2-} / \mathrm{ZrO}_{2}-\mathrm{TiO}_{2}$ catalysts in an extremely low acid system. BioResources 2012, 7, 3984-3998.

13. Bhanja, P.; Modak, A.; Chatterjee, S.; Bhaumik, A. Bifunctionalized mesoporous SBA-15: A new heterogeneous catalyst for the facile synthesis of 5-hydroxymethylfurfural. ACS Sustain. Chem. Eng. 2017, 5, 2763-2773. [CrossRef]

14. Modak, A.; Maegawa, Y.; Goto, Y.; Inagaki, S. Synthesis of 9,9'-spirobifluorene-based conjugated microporous polymers by $\mathrm{FeCl}_{3}$-mediated polymerization. Polym. Chem. 2016, 7, 1290-1296. [CrossRef]

15. Maya, E.M.; Valverde-Gonzalez, A.; Iglesias, M. Conversion of $\mathrm{CO}_{2}$ into chloropropene carbonate catalyzed by iron (II) phthalocyanine hypercrosslinked porous organic polymer. Molecules 2020, 25, 4598. [CrossRef]

16. Modak, A.; Bhanja, P.; Selvaraj, M.; Bhaumik, A. Functionalized porous organic materials as efficient media for the adsorptive removal of $\mathrm{Hg}$ (II) ions. Environ. Sci. Nano 2020, 7, 2887-2923. [CrossRef]

17. Modak, A.; Bhaumik, A. High-throughput acid-base tandem organocatalysis over hollow tube-shaped porous polymers and carbons. ChemistrySelect 2016, 1, 1192-1200. [CrossRef]

18. Goodman, E.D.; Zhou, C.; Cargnello, M. Design of organic/inorganic hybrid catalysts for energy and environmental applications. ACS Cent. Sci. 2020, 6, 1916-1937. [CrossRef]

19. Garcia-Garcia, P.; Moreno, J.M.; Diaz, U.; Bruix, M.; Corma, A. Organic-inorganic supramolecular solid catalyst boosts organic reactions in water. Nat. Commun. 2016, 7, 10835. [CrossRef]

20. Dong, K.; Zhang, J.; Luo, W.; Su, L.; Huang, Z. Sulfonated hyper-cross-linked polymer in DMSO. Chem. Eng. J. 2018, 334, 1055-1064. [CrossRef]

21. Modak, A.; Pramanik, M.; Inagaki, S.; Bhaumik, A. A triazine functionalized porous organic polymer: Excellent $\mathrm{CO}_{2}$ storage material and support for designing Pd nanocatalyst for C-C cross-coupling reactions. J. Mater. Chem. A 2014, 2, 11650. [CrossRef]

22. Modak, A.; Nandi, M.; Mondal, J.; Bhaumik, A. Porphyrin based porous organic polymers: Novel synthetic strategy and exceptionally high $\mathrm{CO}_{2}$ adsorption capacity. Chem. Commun. 2012, 48, 248-250. [CrossRef]

23. Modak, A.; Bhaumik, A. Surface-exposed Pd nanoparticles supported over nanoporous carbon hollow tubes as an efficient heterogeneous catalyst for the C-C bond formation and hydrogenation reactions. J. Mol. Catal. A Chem. 2016, 425, 147-156. [CrossRef]

24. Peng, Y.; Hu, Z.; Gao, Y.; Yuan, D.; Kang, Z.; Qian, Y.; Yan, N.; Zhao, D. Synthesis of a sulfonated two-dimensional covalent organic framework as an efficient solid acid catalyst for biobased chemical conversion. ChemSusChem. 2015, 8, 3208-3212. [CrossRef] [PubMed]

25. Du, M.; Agrawal, A.M.; Chakraborty, S.; Garibay, S.J.; Limvorapitux, R.; Choi, B.; Madrahimov, S.T.; Nguyen, S.T. Matching the activity of homogeneous sulfonic acids: The fructose-to-HMF conversion catalyzed by hierarchically porous sulfonic-acidfunctionalized porous organic polymer (POP) catalysts. ACS Sustain. Chem. Eng. 2019, 7, 8126-8135. [CrossRef]

26. Guo, Z.; Du, F.; Ren, D.; Chen, Y.; Zheng, J.; Liu, Z.; Tian, J. Covalently porphyrin-functionalized single-walled carbon nanotubes: A novel photoactive and optical limiting donor-acceptor nanohybrid. J. Mater. Chem. 2006, 16, 3021-3030. [CrossRef]

27. Yu, H.; Jin, Y.; Li, Z.; Peng, F.; Wang, H. Synthesis and characterization of sulfonated single-walled carbon nanotubes and their performance as solid acid catalyst. J. Solid State Chem. 2008, 181, 432-438. [CrossRef]

28. Modak, A.; Bhanja, P.; Bhaumik, A. Pt nanoparticles supported over porous porphyrin nanospheres for chemoselective hydrogenation reactions. ChemCatChem 2019, 11, 1977-1985. [CrossRef]

29. Mohan, R.; Modak, A.; Schechter, A. Plasma-modified FeGly/C as a Pt-free stable ORR electrocatalyst in an acid electrolyte. ACS Appl. Energy Mater. 2021, 4, 564-574. [CrossRef]

30. Modak, A.; Das, S.; Chanda, D.K.; Samanta, A.; Jana, S. Thiophene containing microporous and mesoporous nanoplates for separation of mercury from aqueous solution. New J. Chem. 2019, 43, 3341-3349. [CrossRef]

31. Quereshi, S.; Ahmad, E.; Pant, K.K.; Dutta, S. Insights into microwave-assisted synthesis of 5-ethoxymethylfurfural and ethyl levulinate using tungsten disulfide as a catalyst. ACS Sustain. Chem. Eng. 2020, 8, 1721-1729. [CrossRef]

32. Sarpiri, J.N.; Chermahini, A.N.; Saraji, M.; Shahvar, A. Dehydration of carbohydrates into 5 hydroxymethylfurfural over vanadyl pyrophosphate catalysts. Renew. Energy 2021, 164, 11-22. [CrossRef]

33. De, S.; Dutta, S.; Saha, B. Microwave assisted conversion of carbohydrates and biopolymers to 5-hydroxymethylfurfural with aluminium chloride catalyst in water. Green Chem. 2011, 13, 2859-2868. [CrossRef] 
34. Guo, W.; Zhang, Z.; Hacking, J.; Heeres, H.J.; Yue, J. Selective fructose dehydration to 5-hydroxymethylfurfural from a fructoseglucose mixture over a sulfuric acid catalyst in a biphasic system: Experimental study and kinetic modelling. Chem. Eng. J. 2021, 409, 128182. [CrossRef]

35. Villa, A.; Schiavoni, M.; Fulvio, P.F.; Mahurin, S.M.; Dai, S.; Mayes, R.T.; Veith, G.M.; Prati, L. Phosphorylated mesoporous carbon as effective catalyst for the selective fructose dehydration to HMF. J. Energy Chem. 2013, 22, 305-311. [CrossRef]

36. Carlini, C.; Giuttari, M.; Galletti, A.M.R.; Sbrana, G.; Armaroli, T.; Busca, G. Selective saccharides dehydration to 5-hydroxymethyl2-furaldehyde by heterogeneous niobium catalysts. Appl. Catal. A Gen. 1999, 183, 295-302. [CrossRef]

37. Antonetti, C.; Melloni, M.; Licursi, D.; Fulignati, S.; Ribechini, E.; Rivas, S.; Parajó, J.C.; Cavani, F.; Galletti, A.M.R. Microwaveassisted dehydration of fructose and inulin to HMF catalyzed by niobium and zirconium phosphate catalysts. Appl. Catal. B Environ. 2017, 206, 364-377. [CrossRef]

38. Deng, T.; Li, J.; Yang, Q.; Yang, Y.; Lv, G.; Yao, Y.; Qin, L.; Zhao, X.; Cui, X.; Hou, X. A selective and economic carbon catalyst from waste for aqueous conversion of fructose into 5-hydroxymethylfurfural. RSC Adv. 2016, 6, 30160-30165. [CrossRef]

39. Son, P.A.; Nishimura, S.; Ebitani, K. Synthesis of levulinic acid from fructose using Amberlyst-15 as a solid acid catalyst. React. Kinet. Mech. Catal. 2012, 106, 185-192. [CrossRef]

40. Testa, M.L.; Miroddi, G.; Russo, M.; Parola, V.L.; Marcì, G. Dehydration of fructose to 5-HMF over acidic TiO $\mathrm{H}_{2}$ catalysts. Materials 2020, 13, 1178. [CrossRef] [PubMed]

41. Yabushita, M.; Li, P.; Islamoglu, T.; Kobayashi, H.; Fukuoka, A.; Farha, O.K.; Katz, A. Selective metal-organic framework catalysis of glucose to 5-hydroxymethylfurfural using phosphate-modified NU-1000. Ind. Eng. Chem. Res. 2017, 56, 7141-7148. [CrossRef]

42. Wang, L.; Zhang, L.; Li, H.; Ma, Y.; Zhang, R. High selective production of 5-hydroxymethylfurfural from fructose by sulfonic acid functionalized SBA-15 catalyst. Comp. Part B Eng. 2019, 156, 9488-9489. [CrossRef]

43. Fang, R.; Luque, R.; Li, Y. Efficient one-pot fructose to DFF conversion using sulfonated magnetically separable MOF-derived $\mathrm{Fe}_{3} \mathrm{O}_{4}$ (111) catalysts. Green Chem. 2017, 19, 647-655. [CrossRef]

44. Richter, F.H.; Pupovac, K.; Palkovits, R.; Schuth, F. Set of acidic resin catalysts to correlate structure and reactivity in fructose conversion to 5-hydroxymethylfurfural. ACS Catal. 2013, 3, 123-127. [CrossRef]

45. Siril, P.R.; Cross, H.E.; Brown, D.R. New polystyrene sulfonic acid resin catalysts with enhanced acidic and catalytic properties. J. Mol. Catal. A Chem. 2008, 279, 63-68. [CrossRef] 